\title{
Data regarding physiatric advanced approaches of stabilometric and virtual reality for balance assessment and (re)training in cerebral palsy
}

\author{
Radu Mihai AVRAM ${ }^{1,3}$, Gelu ONOSE ${ }^{1,2}$, Liliana PADURE ${ }^{1,3}$ \\ 1"Carol Davila" University of Medicine and Pharmacy, Bucharest, Romania \\ 2"Bagdasar-Arseni" Teaching Emergency Hospital, Bucharest, Romania \\ 3"Dr. N. Robanescu" National Teaching Center for Neuro-psycho-motor Rehabilitation in Children, \\ Bucharest, Romania
}

\begin{abstract}
Introduction. Background. Cerebral palsy (CP) taxonomically encompasses spastic, ataxic dyskinetic and non-classifiable types and, together with the elementary motor deficit, disbalance limits the affected individuals' orthostatic and ambulatory capacity, thus balance rehabilitation representing an important stake in (re)gaining functional autonomy. Physiatric advanced approaches such as those mentioned in the title, for specific equilibrium function evaluation and (re)training, seem to be contributive in this respect.

Material and methods. In order to achieve an adequate documentation in the domain of the above mentioned rather new and complex assessment and rehabilitative procedures, we have conducted a systematic literature review following the methodology of the "Preferred Reporting Items for Systematic Reviews and Meta-Analyzes ("PRISMA"). Pursuing this goal, we searched for eligible (see further in the body text of our work) articles, by specific keywords combinations ("syntaxes" - consensually) in five international medical databases: Elsevier, NCBI/PubMed, NCBI/PMC, Cochrane and PEDro, availing in addition, the ISI Web of Knowledge/Science Database, in order to check if the articles were issued in jornals indexed in there.

Results. After fulfilling the selection/ filtering above mentioned standardized endeavor, it resulted 11 qualified and contributive articles, as well. In purpose to strongly enhance our documentation base, we used also free identified bibliographic resources.

Discussion. There is a current and foreseeable further development in the future - technologically for fabrication and respectively, of their technical performances - including as regards the devices used (also) for stabilometric and virtual reality based equilibrium assessment and rehabilitation in cerebral palsy, considering their beneficial effects. Yet, at least partially, some of them are not completely anodyne.

Conclusion. As in most situations, the related methodology of indication and administration can make the difference - so, an as much as possible exhaustive knowledge in this field, too, is necessary and prone to elicit best post intervention outcomes.
\end{abstract}

Keywords: cerebral palsy, equilibrium disorder, (computerized) stabilometry/static posturography, balance (re)training/rehabilitation, augmented/ virtual reality, (inter)/active (electronic/video)/“serious games", puberty/adolescence 


\section{INTRODUCTION. BACKGROUND}

Together with our brain's development, our bipedal, vertical stance and walking - the former resulting in "hands relieved from body support against gravity" (1), availing dexterity and thus, the unique, among living beings, capability to work, and the latter enabling for cognitive and communication more and more complex capabilities - have decisively contributed to the evolution of the humans, down the ages, towards the contemporary impressive post-industrial, knowledge-based, kind of specific social existence and establishment.

"In addition to motor physiology, virtually any human physiological function is adapted to the bipedal posture and walking, for example breathing, digestion, and excretion" (1) and also "bone and connective tissue metabolism" (2).

So, orthostatism and bipedal gait are decisive for a normal human functioning, practically concerning "all the levels within this describing framework, namely 'Body functions and structures', 'Activities and Participation'" of the World Health Organization (WHO)'s related (relatively new) paradigm: the International Classification of Functioning Disability and Health (ICF-DH) (3), and essentially addressing, at the same time, the personal quality of life (QOL). But, as necessary and important as they are, their physiologic achievement is physically very demanding, and hence, including at risk for falls. On the other hand, the humans are endowed with an extremely sophisticated and efficient, specific, neuro-myo-arthro-kinetic structure to ensure equilibrium and re-balance, too.

Synthetically, through extensive coordination by the nervous system, this important function is normally performed based on peripheral/ascending, proprioceptive (including originating from the neck region) and telereceptive, and respectively, central/descending, motor, inputs, with precise, extended/multimodal, and effective, related feed backs. Specifically, "signals from the tendon organ are transmitted like those from the primary endings of the muscle spindle ("One of the more complex elements of the muscle spindle's function is the gamma efferent system, which involves the gamma motor neurons" (5) - with role including in decrement/modulation of the body's segments motricity when performing gait and bolt (4)) into local areas of the cord through long fiber pathways such as the spinocerebellar tracts into the cerebellum through other tracts to the cerebral cortex" (4).

Biunivocal, the gamma efferent system receives, via the spinal cord - through the vestibulospinal and reticulospinal tracts - related " efferent (motor) input from the central nervous system" (5), specifically: commands of brain stem (its bulbo-reticular facilitatory region and the vestibular nuclei) and - intermediate via this above mentioned structure -, also of cerebellar, basal ganglia, and cortical, origin. Thereby, a both prompt and subtle automated, including multi-reflex performed, control of the antigravitational muscles (by combined reciprocal interfering, stimulatory and inhibitory signals - on agonists/antagonists/synergists/stabilizers) is permanently exerted, providing equilibrium (4) in static and dynamic circumstances.

Extremely important involvement in providing balance have also the cerebellum and the basal ganglia, essentially responsible for integration, including of steric sensory kind of information - through very sophisticated circuitry connections - in between and with the cortex and its downward to the spinal cord conveying motor orders - fascicles, and respectively, for the feed backs based modulation/tuning of sequential, coordinated, movements' planification and execution - within adequate cognitive control of them and of the muscle tone.(4), including, as for the cerebellum, with directing and also braking of movements - thus making them smooth and precisely space/objects driven, within adequate proportions between dynamic interplay segmental muscle function states. Therefore, one of the clinical consequences of cerebellar dysfunction is (cerebellar) ataxia $(4,6)$.

An essential role in equilibrium have the sensorial structures/analyzers, i. e. the visual and respectively the vestibular (especially) ones as well.

Regarding the former: it gives visual feed back on body posture and movements: specific information, generating eyes position adequacy to head motions', is transmitted, via the medial longitudinal fasciculus, to the brain stem, and (with generating adequate/compensatory directional gaze stabilizing reflexes from its vestibular nuclei to the oculomotor ones) further, including from the cerebellum, too - and/or through reticular tracts - to the parietal lobe of the cortex, in a (primary) center responsible for balance, thus being provided also awareness, in this respect (4).

The involvement/contribution of the vestibular apparatus is based on the related functions of the utricle's and saccule's maculae (important, but not exclusively, through: hair cells, with their cilia, and respectively, statoconia/otoconia/statoliths/otoliths all covered by a gelatinous layer -; they are mechanosensors that transduce the energy of gravity and of acceleration signals, into an electric one - of the nervous influx - firing the specific sensory primary afferent neurons (7) and of the semicircular canals' ampullar ridges, too; from these specialized receptors emerge, via the vestibular nerves, specific signals to the brain stem - specifically to the complex of vestibular nuclei, where these nerves make synapses with the deutoneurons of the ascendent vestibular pathway $(6,8,9,10)-$ productive of including efferent interplay reflex orders, 
through the spinal cord, to the antigravitational muscles, by the vestibulospinal and reticulospinal tracts (4).

The equilibrium function can be disturbed - with, no matter the etiology, very disabling consequences in different neurological conditions, among which: CP.

"Cerebral palsy describes a group of permanent disorders of the development of movement and posture, causing activity limitation, that are attributed to non-progressive disturbances that occurred in the developing fetal or infant brain. The motor disorders of $\mathrm{CP}$ often accompanied by musculoskeletal problems." $(11,12)$

Specifically, in CP, areas more affected by lesions are located in the: parietal lobe - correlating with the composite "gait profile score (GPS)" -, periventricular layer correlating with the Gross Motor Function Classification System (GMFCS) -, corpus callosum (involved in gait disturbances) (13), respectively - with some association with the (more featured) ataxic forms - cerebellum (14), "posterior fossa abnormalities", vermis and (possibly) hydrocephalus (yet, "In ataxic cerebral palsy CT findings are common, but variable") (15)

Consequently, according to the Surveillance of Cerebral Palsy in Europe (SCPE) Collaborative Group, CP is (largely) classified as: spastic, ataxic dyskinetic and non-classifiable $(13,16)$ - and respectively, after the Swedish classification, as: "spastic (hemiplegic, tetraplegic, and diplegic), dyskinetic (dystonic and athetotic), ataxic and unclassified/mixed".(14)

Ataxic forms account for $4 \%$ ("simple ataxia") (17) to $10 \%(18)$ of all the cases of CP.

Balance disorders, in addition to the basic motor deficit, supplementary affect patients with $\mathrm{CP}$ in performing most of the motor acts - especially in the lower limbs (but also with the trunk and indirectly, in the upper limbs, too) - thus contributing significantly to the disability faced by such patients, including/mainly the risk of falls, and with the consequent alteration of their autonomy and quality of life - equilibrium/balance being "a key issue for children with cerebral palsy" (19).

Considering all the above, assessment and training to recover the static and dynamic balance/equilibrium, including in such pathology, is a major rehabilitative target.

Accordingly, physiatric advanced approaches, used in these purposes, are the focus of this paper, specifically of: stabilometric and respectively, augmented/ virtual reality, types.

\section{STABILOMETRIC EVALUATION/QUANTIFIED TESTING AND BALANCE/EQUILIBRIUM (RE) TRAINING, APPROACHES}

The assessment of balance/(re-)balancing, involves clinical tests, like: Romberg (including sensitized),
Babinski-Weil (20), "walking a straight line heel to toe ('tandem walking test')" (21), Sit-to-Stand (STS - "values in seconds or numbers of STS") (22), (timed) "Up \& Go" (23), "Pediatric Balance Scale (PBS(24) - given that $\mathrm{CP}$ is a primary pediatric condition), even Gross Motor Function Measure 66 GMFM (25) - especially as not a few forms of CP are actually mixed, so the balance disorder is due, in varying proportions, also to the elementary motor deficit) and/or Gross Motor Function Classification System (GMFCS (26)), as well as - modern - tests of "stabilometry" ("computerized")/"static posturography" $(27,28)$, which involve the use of related apparatus facilities. In the National Teaching Center for Neuro-psycho-motor Rehabilitation in Children (NTCNRCNR) "Dr. N. Robanescu" we use such tests, as for instance, to calculate the: "Global stability index (based on horizontal bipodal balancing)", "Ellipse area" (in $\mathrm{mm}^{2}$ ), "Standard deviation of the torso (in degrees)", "Average speed of the center of pressure in the antero-posterior direction - AP - (in mm/s) ","Average speed of the center of pressure in the mid-lateral direction $\mathrm{ML}$ - (in mm/s)“ (29), and such like.

To be mentioned that "Stabilometry is the objective study of body sway during quiet standing", by force plates assessed and quantified, entailing (just) orthostatism, without active motions or passive/from outside induced displacements, and that for the upper trunk and extremities such an endeavor may be (also) performed in sitting position (27).
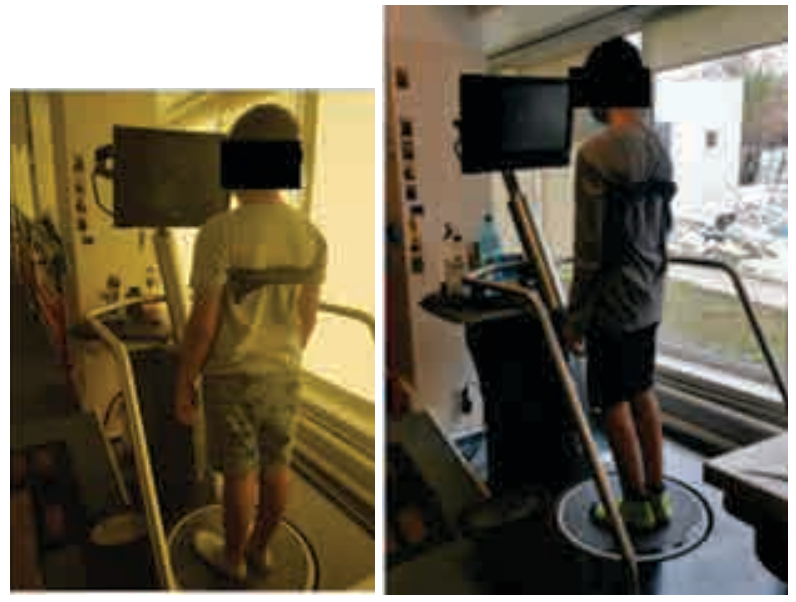

FIGURE 1. Advanced (computerized) stabilometry/ posturographic quantified testing and training apparatus (Pro-Kin 252 (29)), including with visual feed back (from the NTCNRCNR casuistry)

Such type of advanced multipurpose devices, for analysis and training of static and dynamic balance, aims at: body postural, control and coordination regain (including in children with CP $(30,31,32)$, through/including the intervention of the visual analyzer, with consequent reflex adaptive changes in muscle tone maybe even trophicity (33) - and action on different directions of motion, involving the related propriocep- 
tive components, afferent to assisted and coordinated movements, too. In this respect, the electro-mechanical and of "hard" type infrastructure, ensure the sway passive - challenging for re-balancing - movements generated by the force plates of the apparatus, and together with its dedicated software/applications, provide - as continuous guiding/training feedback - the ideal line the patient must follow in order to rehabilitate his/her equilibrium, posture and then/also, gait with consequent decrease of the fall risk (34) - , and further, self-autonomy and consequently, QOL.

Some specific examples, within the, and respectively our, related activity:

1. Romberg test - analyzes the static ("quiet standing") (28) position of the body for a period of $60 \mathrm{sec}-$ onds (30" with eyes open and 30 " eyes closed), through the pressure plate but also by the sensor on the trunk (trunk sensor) - on the xiphoid appendix. The test position is an orthostatic, unshod, standardized, relaxed one, with the feet abducted $10^{\circ}$ and (or parallel - o. $\mathrm{n}$. - according to the workbook (29) of the related device in the NTCNRCNR endowment) and the heels spaced 3 $\mathrm{cm}$ in between, in frontal plane, the upper extremities along with the body, and the eyes open (28), and the gaze focusing on a screen, at a distance of about 1 meter.

2. The test "Stability Index"/Balance Both Feet" (29) (global, based on horizontal bipodal balancing) - to assess dynamic balance: the patient's ability to stabilize his/her self in conditions of instability - also measures the distance between the patient's center of mass and the center of the plate in a 30" duration (with eyes open) with trunk sensor, placed on the xiphoid appendix. This parameter allows the understanding of the global imbalance of the patient in relation to the center of the plate.

In the same standardized stance position, as described above, the patient aims to manage the oscilla-
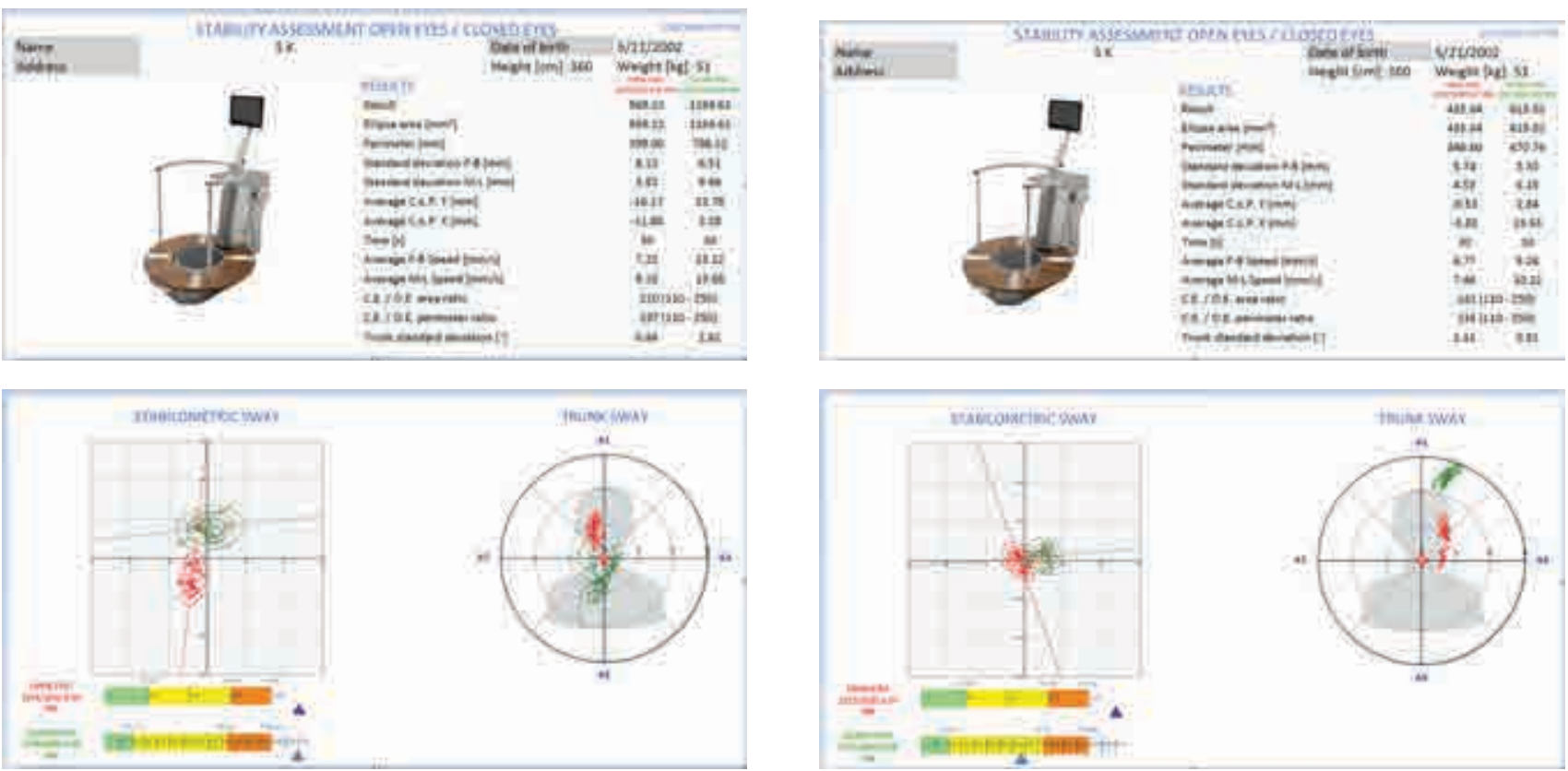

FIGURE 2. Stabilometry/posturographic quantified testing - Romberg test - based on Pro-Kin 252 apparatus dedicated facilities: Patient S.K. (meta-initials) - before treatment (left)* and after treatment (right)* (from the NTCNRCNR casuistry)
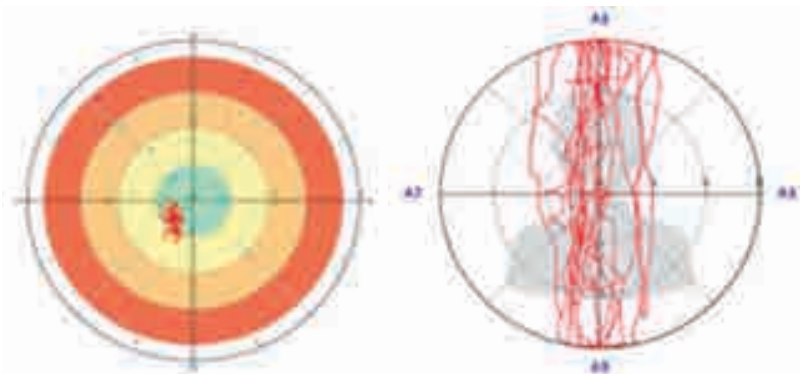

FIGURE 3. The graph represents the kinetic station (ball of yarn) of the two-dimensional circulation movement of the pressure center on the support surface (as shown in Fig. 2 before treatment)
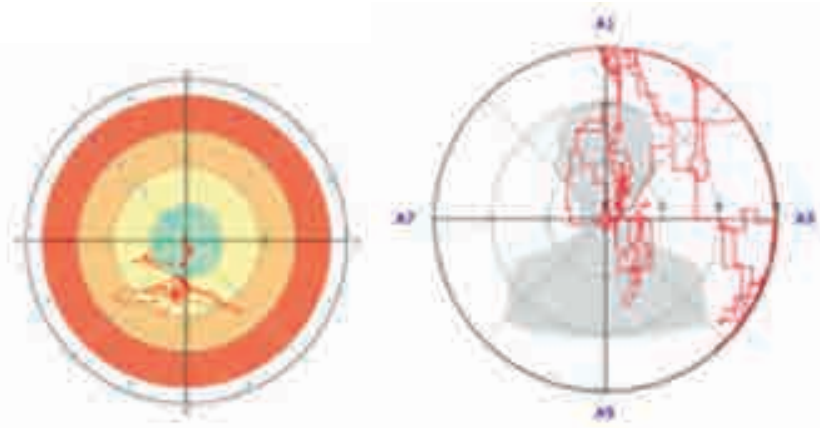

FIGURE 4. The graph represents the kinetic station (ball of yarn) of the two-dimensional circulation movement of the pressure center on the support surface (as shown in Fig. 2 after treatment) 

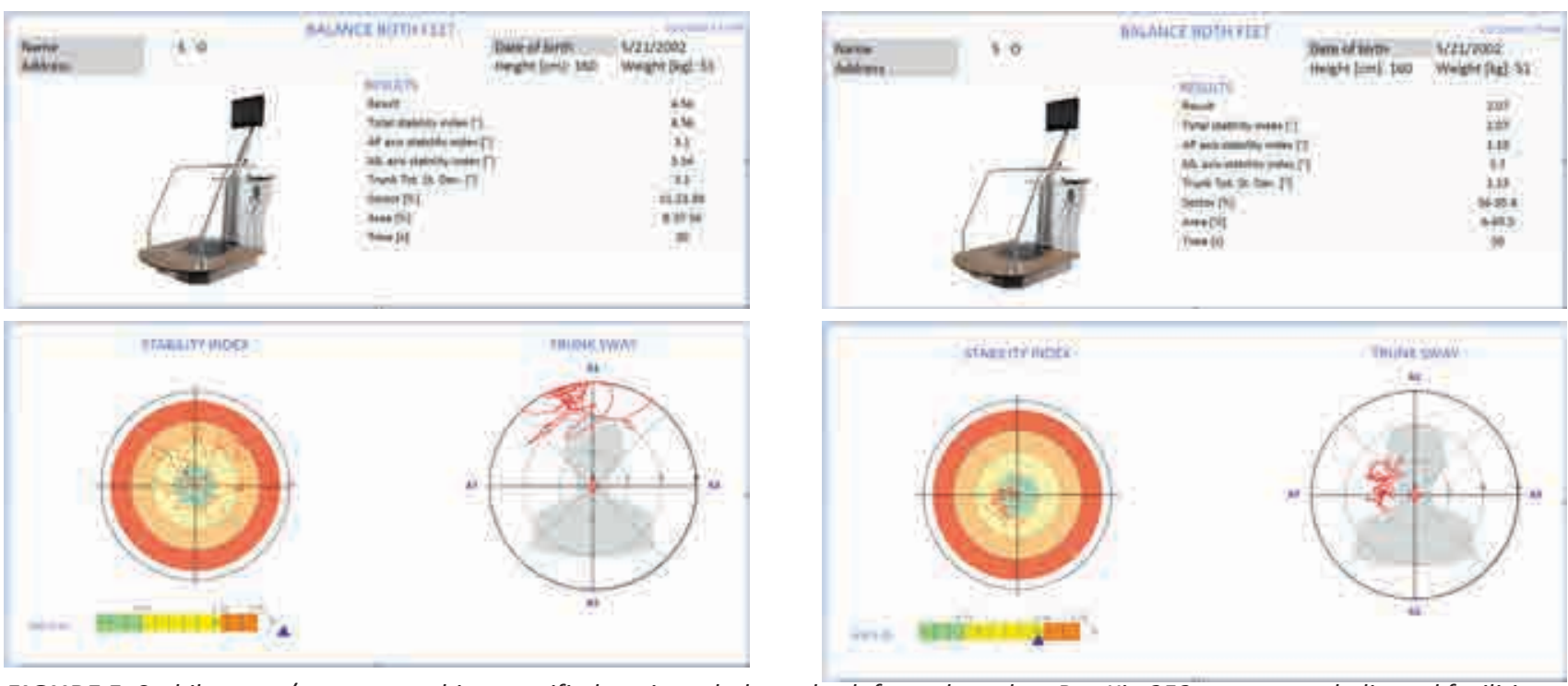

FIGURE 5. Stabilometry/posturographic quantified testing - balance both feet - based on Pro-Kin 252 apparatus dedicated facilities: Patient S.O. (meta-initials) - before treatment (left)* and after treatment (right)* (from the NTCNRCNR casuistry)

tions of the body - benefiting of the intervention of the visual analyzer, too - in order to maintain the center of mass inside the supporting polygon as close as possible to the centriode.

\section{USE OF SENSOR-BASED ADVANCED DEVICES}

Sensor-based advanced devices include computer-originating augmented/virtual reality (AR/VR), providing "inter"/"active (electronic/video) (35-39) / "serious games" (SGs) $(40,41)$ (also) for testing (contingent quantified) and balance/equilibrium rehabilitation.

As known - and we could determine this, too, within our clinical endeavors on the subject we apporach an essential issue in the Pediatric Rehabilitation, including with the NeuroRehabilitation of children and adolescents with $\mathrm{CP}$, is the maintaining of the overall availability - interest, focus, motivation and thereby, cooperation - of such patients for the related (re-) training programs. Therefore, merging them with game facilities is practically mandatory for having good results. Hence, gaming consistently contributes (also) to the education/"habilitation", enhancing - in a pleasant, adequate, way - the development of "communication, learning and socializing" (42) performances, as well as of the self-assertion, including with a better, motivated cooperation in practising recommended therapeutic exercises, including with the adjustable use of related devices - even some of them advanced (42).

To be mentioned first that - for safety (43) reasons the headsets for VR are permited for persons 13 and over years old, as there are some risks of of side effects: "from eye strain and headaches to nausea and, in rare cases, seizures" (44) - we use AR/VR to (re-)train only adolescents, including with in CP. As a necessary related specification: "In principle, puberty would begin around the age of (8)-10 years, continuing with adolescence: from about 13 years to about 19 years (therefore including in Romania - an individual is considered an adult, from all points of view, at the age of 18)" (45).

Accordingly, considering also the benefits of such advanced kinds of therapeutic-habilitative/re-habilitative interventions, a crucial goal - including objective of ours - is to establish the optimal dose for the administration of $A R / V R$ procedures - including in adolescents with PC.

Consequently, we conducted a systematic literature review, according to the standardized methodology, accepted and used internationally: "Preferred Reporting Items for Systematic Reviews and Meta-Analyses ("PRISMA") (46), initiated by interrogating medical databases, on specific key words combinations ("syntaxes" - consensually applied) - as shown in Table 1.

For this purpose we quested five prestigious internationally recognized databases: Elsevier (47), NCBI/ PubMed (48), NCBI/PMC6 (48), Cochrane (49), PEDro (50), additionally using the famous ISI (Institute for Scientific Information - ex Thomson Reuters - currently administered by Clarivate Analytics) Web of Knowledge/Science (51-53) database to check if the articles identified according to the above mentioned - and displayed in Table 1 - key words combinations ("syntaxes" - contextually applied - see Table 1), by which we have searched for the bibliographic resources related to our systematic literature review, are issued in ISI indexed publications. 
TABLE 1. The keywords combinations/syntaxes we used contextually for the initial search, in international medical databases

\begin{tabular}{|l|c|c|c|c|c|}
\hline Keywords & Elsevier & PubMed & PMC & PEDro & Total \\
\hline $\begin{array}{l}\text { "virtual reality" + "cerebral palsy" + } \\
\text { "adolescence" + "dose" }\end{array}$ & 0 & 0 & 14 & 0 & 14 \\
\hline $\begin{array}{l}\text { "augmented reality" + "cerebral palsy" + } \\
\text { "adolescence" + "dose" }\end{array}$ & 0 & 0 & 3 & 0 & $\mathbf{3}$ \\
\hline $\begin{array}{l}\text { "immersive virtual reality" + "cerebral palsy" + } \\
\text { "adolescence" + "dose" }\end{array}$ & 0 & 0 & 0 & 0 & $\mathbf{0}$ \\
\hline $\begin{array}{l}\text { "virtual reality" + "cerebral palsy" + } \\
\text { "adolescent" + "dose" }\end{array}$ & 0 & 0 & 35 & 0 & $\mathbf{3 5}$ \\
\hline $\begin{array}{l}\text { "augmented reality" + "cerebral palsy" + } \\
\text { "adolescent" + "dose" }\end{array}$ & 0 & 0 & 4 & 0 & $\mathbf{4}$ \\
\hline $\begin{array}{l}\text { "immersive virtual reality" + "cerebral palsy" + } \\
\text { "adolescent" + "dose" }\end{array}$ & 0 & 0 & 5 & 0 & $\mathbf{5}$ \\
\hline $\begin{array}{l}\text { "virtual reality" + "cerebral palsy" + } \\
\text { "adolescents" + "dose" }\end{array}$ & 0 & 0 & 51 & 0 & $\mathbf{5 1}$ \\
\hline $\begin{array}{l}\text { "augmented reality" + "cerebral palsy" + } \\
\text { "adolescents" + "dose" }\end{array}$ & 0 & 0 & 4 & 0 & $\mathbf{4}$ \\
\hline $\begin{array}{l}\text { "immersive virtual reality" + "cerebral palsy" + } \\
\text { "adolescents" + "dose" }\end{array}$ & 0 & 0 & 4 & 0 & $\mathbf{4}$ \\
\hline Total & $\mathbf{0}$ & $\mathbf{0}$ & $\mathbf{1 2 0}$ & $\mathbf{0}$ & $\mathbf{1 2 0}$ \\
\hline
\end{tabular}

Our search encompassed five stages, described in detail in a related adapted flow diagram of the PRISMA filtering/selection method, but without the final stage of meta-analysis (see figure 6).

As starting point, we searched, by the already mentioned keywords combinations/syntaxes - used contextually - only for "open access" articles, written in English, published during 01 January 2009 - 31 December, 2019, in ISI indexed journals, and located in the 5 mentioned databases (with the removal of the duplicates). After aplying an adapted prelimnary indirect qualitative selection algorithm based on related quotations weighted average (54), inspired by the classification criteria of the Physiotherapy Evidence Database (PEDro), and based on using the PEDro (55) score, we considered eligible only the articles that reached at least four points ("fair quality = PEDro score 4-5") or more.
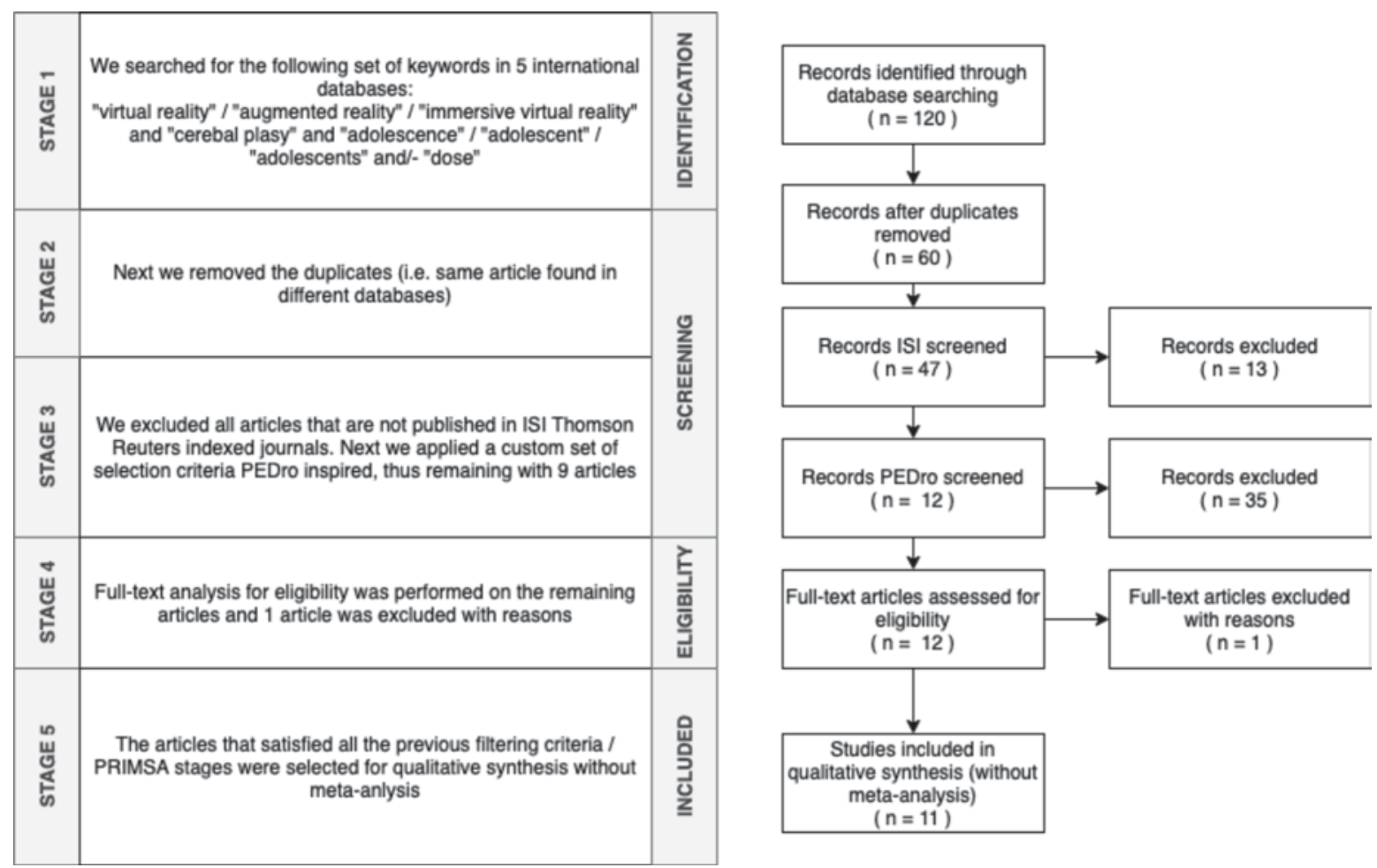

FIGURE 6. PRISMA-type flow diagram, adapted to our query/filtering for related articles 
TABLE 2. The articles we have selected through the PRISMA filtering method, within our systematic literature review

\begin{tabular}{|c|c|c|c|}
\hline Article & Pub. Year & $\begin{array}{l}\text { Citation } \\
\text { Count }\end{array}$ & $\begin{array}{l}\text { PEDro } \\
\text { Score }\end{array}$ \\
\hline $\begin{array}{l}\text { Blank et al. International clinical practice recommendations on the definition, } \\
\text { diagnosis, assessment, intervention, and psychosocial aspects of developmental } \\
\text { coordination disorder. Dev Med Child Neurol. 2019;61(3):242-285. }\end{array}$ & 2019 & 126 & 10 \\
\hline $\begin{array}{l}\text { Hatem et al. Rehabilitation of Motor Function after Stroke: A Multiple Systematic } \\
\text { Review Focused on Techniques to Stimulate Upper Extremity Recovery. Front Hum } \\
\text { Neurosci. 2016;10:442. }\end{array}$ & 2016 & 358 & 10 \\
\hline $\begin{array}{l}\text { Li LM, Uehara K, Hanakawa T. The contribution of interindividual factors to } \\
\text { variability of response in transcranial direct current stimulation studies. Front Cell } \\
\text { Neurosci. 2015;9:181. }\end{array}$ & 2015 & 265 & 10 \\
\hline $\begin{array}{l}\text { Novak I, Honan I. Effectiveness of paediatric occupational therapy for children with } \\
\text { disabilities: A systematic review. Aust Occup Ther J. 2019; 66(3): 258-273. }\end{array}$ & 2019 & 41 & 10 \\
\hline $\begin{array}{l}\text { LeBlanc et al. Active Video Games and Health Indicators in Children and Youth: A } \\
\text { Systematic Review. PLoS One. 2013;8(6):e65351. }\end{array}$ & 2013 & 40 & 10 \\
\hline $\begin{array}{l}\text { Galna et al. Retraining function in people with Parkinson's disease using the } \\
\text { Microsoft kinect: game design and pilot testing. J Neuroeng Rehabil. 2014;11:60. }\end{array}$ & 2014 & 150 & 7 \\
\hline $\begin{array}{l}\text { Hoffman et al. Immersive Virtual Reality as an Adjunctive Non-opioid Analgesic } \\
\text { for Pre-dominantly Latin American Children With Large Severe Burn Wounds } \\
\text { During Burn Wound Cleaning in the Intensive Care Unit: A Pilot Study. Front Hum } \\
\text { Neurosci. 2019;13:262. }\end{array}$ & 2019 & 22 & 6 \\
\hline $\begin{array}{l}\text { Sakti Prasad Das, G Shankar Ganesh. Evidence-based Approach to Physical Therapy } \\
\text { in Cerebral Palsy, Indian J Orthop. 2019;53(1):20-34. }\end{array}$ & 2019 & 21 & 6 \\
\hline $\begin{array}{l}\text { Morone et al. The Efficacy of Balance Training with Video Game-Based Therapy } \\
\text { in Subacute Stroke Patients: A Randomized Controlled Trial. Biomed Res Int. } \\
\text { 2014;2014:580861. }\end{array}$ & 2014 & 119 & 6 \\
\hline $\begin{array}{l}\text { Zeinab A. Hussein, Ibrahim A. Salem, Mostafa S. Ali. Effect of simultaneous } \\
\text { proprioceptive-visual feedback on gait of children with spastic diplegic cerebral } \\
\text { palsy. J Musculoskelet Neuronal Interact. 2019;19(4):500-506. }\end{array}$ & 2019 & 19 & 5 \\
\hline $\begin{array}{l}\text { Ramezani et al. A Novel Intervention Technology for Cerebral Palsy: Brain } \\
\text { Stimulation. Iran J Child Neurol. } 2019 \text { Spring;13(2):17-28. }\end{array}$ & 2019 & 13 & 4 \\
\hline
\end{tabular}

Eventually, we have selected 12 articles that met the PRISMA selection method criteria (including with the indirect qualitative selection algorithm and related PEDro scoring we applied), and thus improved our documentation through related knowledge data found in 11 of them. Although this systematic literature review complied with the above mentioned method's selection rigors, however, some works of interest could still be missed. On the other hand, as it may be determined, we tried to ensure an as large as possible documentation - especially as the articles selected are not many - for the subject we have overall approached, using also bibliographic resources freely found in the literature.

"Virtual reality (VR) or virtual environment (VE) can be defined as a computing technology that generates simulated or artificially three dimensional (3D) environment, which imitates reality."; in principle, its infrastructure (hard and soft-ware) must produce a "convincing" artificial milieu prone to allow the user to interfere with it as "naturalistic" as possible (56).

Since the beginning, it is necessary to make a related detailing: encompassing aside VR, there is Augmented Reality (AR), i. e. a number of computer-based facilities to enhance multisensory perceptions, through additional stimuli such as - aside visual ones - hearing, olfactory and/or tactile, kinds - many of them merging with the physical surrounding (of which the user is not disconnected) specifically, by adding/superposing to reality " synthetic elements like 3D objects, multimedia contents or text information onto real-world images", in order, as above mentioned, to enhance the human-digital ambient multimodal interactivity (57).

Thus, AR/ VR can create and artificial VE the user can interact with and explore/ exercise acts similar (to) those of the real life.

Some examples - of many alike - are the "serious games": Snowball Fight (in which the patient uses a Wii Remote $(57,58))$, respectively the ones we use currently, as described below.

a. Cutting fruits: for patients with consequent to $\mathrm{CP}$ so-called crouch (hip and knee flexion, and leg dorsiflexion) or hemiplegia, in which they attempt to transfer reciprocally their body weight from the healthy limb to the affected one, in order to increase the base support that enhances stability in orthostatism (maybe leading to improved bone density, too). Accordingly, the respective patients will perform a dynamic training designed to unbalance them, followed by reactive overall stabilization, through continuous transfer of body weight from one hemi-body to the other [the patient in orthostatism, standing on a balance board, 
moves his/her legs in the middle-lateral (ML) direction and watches the fruits coming in site on a screen (they appear randomly from the bottom of the respective display to the upward direction, and the user tries to cut them before they fall)], following the afferent score to the right side of the screen. Hence, there is motivation to cut as many fruits as possible - to increase the score - in two minutes (on 3 levels of difficulty: easy, hard, extreme), and 15 rounds of play;

b. For patients with ataxia, we target to approach it availing the shoot cutter game: on the balance board, in static/dynamic mode, in two minutes, in orthostatic position, with related postural corrections (axial extension, shoulders in adduction, retro/pelvic anteversion), they have to move their body (weight), represented by the center of pressure (COP - figured on the screen as a blue cross) when random darts are seen on the screen, and maintain such targets in position - while keeping his/her balance, too - for three seconds (to be able, thus, to score). The game has 3 levels of difficulty (easy, hard, extreme) and 15 rounds of play;

c. Piloting an aircraft: from an orthostatic position, with a fixed or dynamic plate, for two minutes, over the metropolises of Europe - aiming to pass through targets in the form of darts that appear randomly on the screen with the COP moving in the antero-posterior (AP) and ML directions. The game has 3 levels of difficulty (easy, hard, extreme) and 15 rounds of play.

d. Ski: from an orthostatic position on a fixed or dynamic board, for a period of two minutes, the patient must place his/her COP in the front plane, for being able to move the skier (avatar); the higher the pressure on the anterior support area the bigger the speed of the skier. In order to slow down, the pressure is applied stronger on the posterior plane (at the same time, for changing direction, the pressure will be exerted in the ML plane). The game has 3 levels of difficulty (easy, hard, extreme) and 15 rounds of play.

e. Equilibrium: the patient is in orthostatic position on a fixed or dynamic plate - for a period of two minutes and must insert a ball into a hole. The game appears in the form of a labyrinth with one or more holes, where the balls must be introduced under the action of the plantar force exerted on the balance board in the AP and ML directions. The game has 3 levels of difficulty (easy, hard, extreme) and 15 rounds of play (29).

There are also expressly conceived such electronically/by information technology (IT) video facilities-generated, rehabilitative instruments, as for instance: "'mirror-like' video or computer graphic setups, where a video or computer graphic image of the moving limb is presented"(59) and/or "Exergames": a type of "motion, balance, and physical fitness" promoting (re)training facilities, entailing an "almost uniformly slow-paced" strongly pro-active pattern, and therefore being useful including to counteract the lack of general voluntary stiring consequent to $\mathrm{CP}(60)$.

Very important is the principle of "biofeedback and virtual reality system": the users - including children and adolescents - are represented, all together, within the artificial surrounding by an "avatar", that reproduces, in trajectories and strength, his/her own motor actions (61). This actually makes the major difference between AR/VR/VE procedures and the simple watching of a screen: the possibility of the user(s), on one hand, to manage his/her "viewpoint" within the VE and on the other, (also) to intervene and produce changes in it (62).

Moreover, such visual feed backs provided, stimulate, through attracting/maintaining the user's (especially child or adolescent) interest/attention and motivation: neuroplasticity (63) - basic intimate support of rehabilitation.

Obviously, like practically, in most cases and types of interventions, the related therapeutic-habilitative/ re-habilitative outcomes are influenced by "interindividual features" (64), too.

To be also specified that in the literature there can be encountered, too, and opinion that such therapeutic-rehabilitative facilities and related procedures including with "robot-assisted therapy (sometimes in combination with virtual reality games)" are not different, regarding the principle of their (re)training capabilities, but rather diverse/"alternative" ways to avail them (65).

Another important specification refers to the fact that the AR/VR/VE - form a technical point of view, but also as its influence on the person placed and acting in such a milieu - differ, including taxonomically, by the level of immersivity: from "non-immersive" - closer to AR (o. n.): (Desktop) Systems, using more or less a common, yet performant (possibly "3D interaction devices" added), digital infrastructure - to semi-immersive (Projection Systems, entailing a superior endowment (more sophisticated imagery/ensembles, respectively also special glasses providing "stereoscopic" vision), to "fully immersive" (utilizing "Head Mounted Displays", that enable for a deepened sense of presence) (66) for some specific clinic indications with possible "adjunctive non-opioid" analgesic effects, too (67).

\section{DISCUSSION}

As IT will develop its technical capabilities/performances, at the same time improving cost-effectiveness, it is to be expected the availability, also for domiciliary use (68), of such advanced devices to enhance.

This comes along with their beneficial, including of therapeutic-rehabilitative kinds, effects, but (in the complex context of effectiveness, profits, and detri- 
ments of brain stimulation techniques in CP (69)), also with the inherent risks related to the excess of their use (see above, plus the possible negative consequences of neuroplasticity excessive stimulation, like for instance: neuropathic pain, movement disorders, tinnitus (70)). Therefore, further/supplementary research is needed to quest, conceptually and methodologically, as well, for the "ways to improve functional outcomes in children with $\mathrm{CP}(71)$.

\section{CONCLUSIONS}

Technological advances and related advanced rehabilitation devices that have thus become available rep- resent an enlargement and improvement of the current panel of approaches, including for adolescents with $\mathrm{CP}$.

But, at the same time, their appropriate use is an important challenge for the physicians and therapists working in this domain, regarding the optimal overall metodology applied - among which the dosage holds a central position.

\section{Acknowledgement}

This work has been achieved within the first author's ensemble of Doctoral - PhD studies - which has the approval of the NTCNRCNR Ethics Commission, with No. 7661/19.10.2017.
Conflict of interest: none declared Financial support: none declared

\section{REFERENCES}

1. Onose G, Cârdei V, Crăciunoiu ŞT et al. Mechatronic Wearable Exoskeletons for Bionic Bipedal Standing and Walking: A New Synthetic Approach. Front Neurosci. 2016 Sep 29;10:343.

2. Uebelhart D, Bernard J, Hartmann DJ et al. Modifications of bone and connective tissue after orthostatic bedrest. Osteoporos Int. 2000;11(1):59-67.

3. $\mathrm{WHO}$ - International Classification of Functioning Disability and Health (ICF), World Health Organization Geneva, 2001. Available at https://www.who.int/standards/ classifications/international-classification-offunctioning-disability-and-health

4. Hall JE, Guyton AC. Cortical and Brain Stem Control of Motor Function (unit XI) - in Guyton and Hall Textbook of Medical Physiology, 12th ed.; Saunders Elsevier: Philadelphia, PA, USA, 2011:667-679.

5. Lowe W. Understanding the Gamma Efferent System; Massage Today; 2017 . Available at https://www.massagetoday.com/ articles/15391/Understanding-the-GammaEfferent-System.

6. Nica S, Davidescu I. Examinarea neurologică. Neurologie, (Vol. I), București: Editura Universitară „Carol Davila“, 2007:102-109.

7. Carey J, Amin N. Evolutionary changes in the cochlea and labyrinth: Solving the problem of sound transmission to the balance organs of the inner ear. Anat $\operatorname{Rec} A$ Discov Mol Cell Evol Biol. 2006 Apr; 288(4):482-9.

8. Minea D, Varga I, Falup-Pecurariu C, Bazele semiologice ale practicii neurologice. Brașov: Universitatea "Transilvania" Brașov, Facultatea de Medicină Generală; 2000:33-39.

9. Ionel C. Compendium de neurologie. București: Editura 100+1 Gramar; 1997:105-107.

10. Lupu G, Cristea B, Terteliu F et al. Anatomia omului. Sistemul nervos central. Lucrări practice. Bucuresti: Editura Universitară, Carol Davila; 2007:36.

11. Rosenbaum $P$, Paneth $N$, Leviton $A$, Goldstein M, Bax M, Damiano D, Dan B, Jacobsson $B$. A report: the definition and classification of cerebral palsy April 2006. Dev Med Child Neurol Suppl. 2007 Feb;109:8-14. Erratum in: Dev Med Child Neurol. 2007 Jun;49(6):480.

12. Bax M, Goldstein M, Rosenbaum P, Leviton A, Paneth N, Dan B, Jacobsson B, Damiano D; Executive Committee for the Definition of Cerebral Palsy. Proposed definition and classification of cerebral palsy, April 2005. Dev Med Child Neurol. 2005 Aug; 47(8):571-6.

13. Papageorgiou E, De Beukelaer N, Simon-Martinez C et al. Structural Brain Lesions and Gait Pathology in Children With Spastic Cerebral Palsy. Frontiers in human neuroscience 2020;14:275.

14. Ogoke CC. Clinical Classification of Cerebral Palsy. 2018. Available at https://www. intechopen.com/books/cerebral-palsyclinical-and-therapeutic-aspects/clinicalclassification-of-cerebral-palsy.

15. Miller G, Cala LA. Ataxic cerebral palsy clinico-radiologic correlations. Neuropediatrics. 1989 May;20(2):84-9.

16. Surveillance of Cerebral Palsy in Europe. Surveillance of cerebral palsy in Europe: a collaboration of cerebral palsy surveys and registers. Surveillance of Cerebral Palsy in Europe (SCPE). Dev Med Child Neurol. 2000 Dec;42(12):816-24.

17. Hagberg B, Hagberg G, Beckung E, Uvebrant $P$. Changing panorama of cerebral palsy in Sweden. VIII. Prevalence and origin in the birth year period 1991-94. Acta Paediatr. 2001 Mar;90(3):271-7.

18. Birth Injury Guide - Ataxic Cerebral Palsy. Available at https://www.birthinjuryguide.org/ cerebral-palsy/types/ataxic/.

19. Wiart L, Rosychuk RJ, Wright FV. Evaluation of the effectiveness of robotic gait training and gait-focused physical therapy programs for children and youth with cerebral palsy: a mixed methods RCT. BMC Neurol. 2016 Jun 2;16:86.

20. Gavriliuc M. Examenul neurologic. Chișinău: Universitatea de Stat de Medicină şi Farmacie „Nicolae Testemiţanu”; 2012.

21. Ropper AH, Samuels MA. Disorders of Stance and Gait (Chpt. 7). Adams and Victor's Principles of Neurology, Ninth Edition, McGraw Hill Comp. Inc., USA; 2009.

22. Frykberg GE, Charlotte K. Häger CK. Movement analysis of sit-to-stand - research informing clinical practice. Physical Therapy Reviews 2015;20(3):156-167.

23. Shumway-Cook A, Brauer S, Woollacott M. Predicting the probability for falls in community-dwelling older adults using the Timed Up \& Go Test. Phys Ther. 2000 Sep; 80(9):896-903.

24. Physiopedia, Pediatric Balance Scale. Available at https://www.physio-pedia.com/ Pediatric_Balance_Scale.

25. Shirley Ryan AbilityLab, Gross Motor Function Measure - 66. Available at https:// www.sralab.org/rehabilitation-measures/ gross-motor-function-measure-66.

26. Palisano R, Rosenbaum P, Walter $S$, Russell D, Wood E, Galuppi B. Development and reliability of a system to classify gross motor function in children with cerebral palsy. Dev Med Child Neurol. 1997 Apr;39(4):214-23.

27. Chiari L. Stabilometry. In: Binder MD, Hirokawa N., Windhorst U. (eds). Encyclopedia of Neuroscience. Berlin: Springer, 2009.

28. Collins JJ, De Luca CJ. Open-loop and closed-loop control of posture: a randomwalk analysis of center-of-pressure trajectories. Exp Brain Res. 1993; 95(2):308-18.

29. Physiomed, Pro-Kin 252.Available at https:// www.physiomed.ro/product/pro-kin-252/.

30. Shumway-Cook A, Hutchinson S, Kartin D, Price $R$ et al. Effect of balance training on recovery of stability in children with cerebral 
palsy. Dev Med Child Neurol. 2003 Sep; 45(9):591-602.

31. Hussein ZA, Salem IA, Ali MS. Effect of simultaneous proprioceptive-visual feedback on gait of children with spastic diplegic cerebral palsy. J Musculoskelet Neuronal Interact. 2019 Dec 1;19(4):500-506.

32. Ali MS, Awad AS, Elassal MI. The effect of two therapeutic interventions on balance in children with spastic cerebral palsy: A comparative study. J Taibah Univ Med Sci. 2019 Jul 26;14(4):350-356.

33. Nam SM, Kim WH, Yun CK. The effects of a multisensory dynamic balance training on the thickness of lower limb muscles in ultrasonography in children with spastic diplegic cerebral palsy. J Phys Ther Sci. 2017 Apr;29(4):775-778.

34. El-Shamy SM, Abd El Kafy EM. Effect of balance training on postural balance control and risk of fall in children with diplegic cerebral palsy. Disabil Rehabil. 2014; 36(14):1176-83.

35. Morone G, Tramontano M, losa M, Shofany J, lemma A, Musicco M, Paolucci S, Caltagirone $C$. The efficacy of balance training with video game-based therapy in subacute stroke patients: a randomized controlled trial. Biomed Res Int. 2014; 2014:580861.

36. Blank R, Barnett AL, Cairney J et al. International clinical practice recommendations on the definition, diagnosis, assessment, intervention, and psychosocial aspects of developmental coordination disorder. Dev Med Child Neurol. 2019 Mar;61(3):242-285.

37. Straker LM, Campbell AC, Jensen LM, Metcalf DR, Smith AJ, Abbott RA, Pollock $\mathrm{CM}$, Piek JP. Rationale, design and methods for a randomised and controlled trial of the impact of virtual reality games on motor competence, physical activity, and mental health in children with developmental coordination disorder. BMC Public Health. 2011 Aug 18;11:654.

38. Boyd RN, Mitchell LE, James ST, Ziviani J, Sakzewski L, Smith A, Rose S, Cunnington R, Whittingham K, Ware RS, Comans TA, Scuffham PA. Move it to improve it (Mitii): study protocol of a randomised controlled trial of a novel web-based multimodal training program for children and adolescents with cerebral palsy. BMJ Open. 2013 Apr 10;3(4):e002853.

39. LeBlanc AG, Chaput JP, McFarlane A et al. Active video games and health indicators in children and youth: a systematic review. PLoS One. 2013 Jun 14;8(6):e65351.

40. Bonnechère $B$, Omelina $L$, Jansen $B$ et al. Balance improvement after physical therapy training using specially developed serious games for cerebral palsy children: preliminary results. Disabil Rehabil. 2017 Feb;39(4):403-406.

41. Michmizos KP, Krebs HI. Serious Games for the Pediatric Anklebot. The Fourth IEEE RAS/EMBS International Conference on Biomedical Robotics and Biomechatronics, Rome, Italy. June 24-27, 2012;1710-1714.
42. Huizinga J. Homo ludens. Încercare de determinare a elementului ludic al culturii, București: Editura Humanitas, 2017.

43. Galna B, Jackson D, Schofield G et al. Retraining function in people with Parkinson's disease using the Microsoft kinect: game design and pilot testing. $J$ Neuroeng Rehabil. 2014 Apr 14;11:60.

44. Hicks M. When is it safe to buy kids a VR headset?; 2018. Available at https://www. techradar.com/how-to/when-is-it-safe-to-buykids-a-vr-headset.

45. Pădure L, Onose G, Mirea A et al. Systematic and synthetic literature review on physiological interrelations between hormones influencing sexual and reproductive functions and bone biology, in puberty and adolescence. Communication at the a XVI-a Conferință Națională de Balneologie și Recuperare Medicală, București, 11 - 13 Aprilie 2019. Available at http://www.inrmfb.ro/wp-content/ uploads/2019/04/VOL_REZ_2019.pdf.

46. Prisma 2009 Flow Diagram. Available at http://prisma-statement.org/documents/ PRISMA\%202009\%20flow\%20diagram.pdf.

47. Elsevier. Available at https://www.elsevier. $\mathrm{com} /$.

48. NCBI Resources. Available at https://www. ncbi.nlm.nih.gov (PubMed)/ (PMC).

49. Cochrane Library. Available at https://www. cochranelibrary.com/.

50. Physiotherapy Evidence Database .Available at http://search.pedro.org.au/search.

51. Web of Science. Available at https://apps. webofknowledge.com.

52. Clarivate Analytics. Acquisition of the Thomson Reuters Intellectual Property and Science Business by Onex and Baring Asia Completed. Available at https://www. prnewswire.com/news-releases/acquisitionof-the-thomson-reuters-intellectual-propertyand-science-business-by-onex-and-baringasia-completed-300337402.html.

53. Web of Science Group. Available at https:// mjl.clarivate.com/home.

54. Onose G, Popescu N, Munteanu C, Ciobanu V, Sporea C, Mirea MD, Daia C, Andone I, Spînu A, Mirea A. Mobile Mechatronicl Robotic Orthotic Devices to AssistRehabilitate Neuromotor Impairments in the Upper Limb: A Systematic and Synthetic Review. Front Neurosci. 2018 Sep 5;12:577.

55. Stroke Engine. PEDro score. Available at https://strokengine.ca/glossary/pedro-score/.

56. Ma $\mathrm{M}$, Zheng $\mathrm{H}$. Virtual reality and serious games in healthcare (Chapter 9). In: Brahnam S, Jain LC (Eds.). Advanced computational intelligence paradigms in healthcare; 2016:169-192.

57. Martín-Gutiérrez J, Mora CE, Añorbe-Díaz B et al. Virtual technologies trends in education. EURASIA J Math Sci Technol Ed; 2017:469-486.

58. Anderson F, Annett M, Bischof WF. Lean on Wii: physical rehabilitation with virtual reality Wii peripherals. Stud Health Technol Inform. 2010;154:229-34.
59. Hatem SM, Saussez G, Della Faille M, Prist $V$, Zhang X, Dispa D, Bleyenheuft Y.

Rehabilitation of Motor Function after Stroke: A Multiple Systematic Review Focused on Techniques to Stimulate Upper Extremity Recovery. Front Hum Neurosci. 2016 Sep 13;10:442.

60. Hernandez HA, Ye Z, Nicholas Graham TC et al.Designing Action-Based Exergames for Children with Cerebral Palsy. Conference: Proceedings of the SIGCHI Conference on Human Factors in Computing Systems; 2013.

61. Wiart L, Rosychuk RJ, Wright FV. Evaluation of the effectiveness of robotic gait training and gait-focused physical therapy programs for children and youth with cerebral palsy: a mixed methods RCT. BMC Neurol. 2016 Jun 2;16:86.

62. Wilson PN, Foreman N, Tlauka M. Transfer of spatial information from a virtual to a real environment in physically disabled children. Disabil Rehabil. 1996 Dec;18(12):633-7.

63. Huang $\mathrm{H}$, Wolf SL, He J. Recent developments in biofeedback for neuromotor rehabilitation. J NeuroEngineering Rehabil. 2006;3:11.

64. Li LM, Uehara K, Hanakawa T. The contribution of interindividual factors to variability of response in transcranial direct current stimulation studies. Front Cell Neurosci. 2015 May 12;9:181.

65. Basu AP, Pearse J, Kelly S, Wisher V, Kisler J. Early intervention to improve hand function in hemiplegic cerebral palsy. Front Neurol. 2015 Jan 6;5:281.

66. Types of VR system. Available at http://www. agocg.ac.uk/reports/virtual/37/chapter2.htm.

67. Hoffman HG, Rodriguez RA, Gonzalez M, Bernardy M, Peña R, Beck W, Patterson DR, Meyer WJ 3rd. Immersive Virtual Reality as an Adjunctive Non-opioid Analgesic for Pre-dominantly Latin American Children With Large Severe Burn Wounds During Burn Wound Cleaning in the Intensive Care Unit: A Pilot Study. Front Hum Neurosci. 2019 Aug 8;13:262.

68. Novak I, Honan I. Effectiveness of paediatric occupational therapy for children with disabilities: A systematic review. Aust Occup Ther J. 2019 Jun;66(3):258-273.

69. Ramezani S, Amiini N, Khodaei F, Safakheil H, Sarveazad A, Mohebbi SL, Brouki Milan P. A Novel Intervention Technology for Cerebral Palsy: Brain Stimulation. Iran J Child Neurol. 2019 Spring;13(2):17-28.

70. Muresanu DF. Neuromodulation with pleiotropic and multimodal drugs -- future approaches to treatment of neurological disorders. Acta Neurochir Suppl. 2010; 106:291-4.

71. Das SP, Ganesh GS. Evidence-based Approach to Physical Therapy in Cerebral Palsy. Indian J Orthop. 2019 Jan-Feb; 53(1):20-34. 